\title{
An audit of orthopedic operation notes: what are we missing?
}

\author{
This article was published in the following Dove Press journal: \\ Clinical Audit \\ II May 2010 \\ Number of times this article has been viewed
}

\section{A K Ghosh \\ William Harvey Hospital, Ashford, UK}

Correspondence: A K Ghosh

William Harvey Hospital, Kennington

Road, Ashford TN24 0LZ,

United Kingdom

Email: arijitkg@hotmail.com
Abstract: The importance of complete and legible operation notes is indisputable. Orthopedic operation notes at the author's institution were audited against guidelines regarding content and legibility. Although of generally good standard it was found that in some cases important information was being missed and that a high proportion of notes had sections that were deemed illegible. A computerized proforma for writing notes has been proposed.

Keywords: orthopedic, operation notes, audit

\section{Introduction}

Operation notes are the only record of an operation. The operative findings and post operative plans they contain, serve not only as a vital means of communication between health professionals, but are also the only legal record of an operation. ${ }^{1}$ Its importance is recognized by the General Medical Council who state that good note keeping is an essential part of good medical practice ${ }^{2}$ while the British Orthopedic Association state that "good records are a basic tool of clinical practice". ${ }^{3}$ However, The National Confidential Enquiry into Perioperative Deaths ${ }^{4}$ in the UK noted that orthopedic operative records were often inadequate describing examples as "untidy one liners". The literature also shows that a proportion of litigation is against an alleged substandard quality of surgery and that poor operation notes mainly involving incomplete illegible notes and the use of confusing abbreviations are a common source of weakness in the surgeon's defence. ${ }^{5}$

A pubmed search using the terms 'operation', 'notes', and 'orthopedic' resulted in 124 results. Of these, three were relevant. ${ }^{1,6,7}$ These studies included auditing only elective total knee replacement consent forms against British Orthopedic Association guidelines ${ }^{6}$ and auditing all orthopedic operations at the institution against authors criteria. ${ }^{7}$ To our knowledge this is the only known study auditing all orthopedic operations at a given institution against set guidelines.

The Royal College of Surgeons of England has recently published the booklet Good Surgical Practice ${ }^{8}$ which contains a section on record keeping. This section contains recommendations regarding details that should be documented to create complete and comprehensive operation notes (Figure 1). Operation notes at the author's institution were audited against these guidelines.

The aim of this paper is to review operation notes (trauma and elective) to determine whether they meet recommendations as set out in Good Surgical Practice. ${ }^{8}$ submit your manuscript $\mid$ www.dovepress.com 


\section{Methods}

The audit was carried out at the author's institution, which is a district general hospital providing a trauma and elective orthopedic service. On two separate occasions, in June and September 2009, operation notes of all inpatients were reviewed. Operation notes were reviewed by a single observer and matched against criteria as set out in Good Surgical Practice. ${ }^{8}$ In areas of illegibility the criteria was marked as not filled.

\section{Results}

A total of 47 operation notes were reviewed of which 25 (53\%) were elective cases and 22 (47\%) were trauma cases. Elective cases were predominantly total hip and knee replacements while trauma cases were varied. Trauma cases included mainly surgery for proximal femoral fractures (dynamic hip screw and hemiarthroplasty), but also included open reduction and internal fixation of ankle, tibia, femur, humerus, radius, and ulna, as well as olecranon tension band wiring and a quadriceps tendon repair. In total the 47 cases noted had been performed by 12 surgeons. Of these, 24 cases were performed by consultants as the main surgeon, 19 by registrars, and four cases by senior house officer (SHO) level trainees. In all cases of middle or junior surgeons the main operating surgeon had written the operation notes, while in cases by consultants 10 cases (42\%) had been written by the assistant. As such the operation notes audited had been written by a total of 11 surgeons of varying experience.

Two cases (4\%) had no documentation of date, while only 21 cases (45\%) had documented time (anesthetic notes

- Date and time

- Elective/emergency

- Names of operating surgeon and assistant

- Operative procedure carried out

- Incision

- Operative diagnosis

- Operative findings

- Any problems/complications

- Extra procedure performed and reason why also reviewed). No case documented whether the operation in question had been performed as an elective or emergency case, although this could be discerned from type of operation. All cases $(100 \%)$ clearly documented consultants and operating surgeon's names. However, five cases (10\%), in which an assistant would normally be required, had no documentation of an assistant's name. Operation notes audited were therefore subsequently compared against computerized logbooks of cases kept in theater. This demonstrated a discrepancy in assistants present in $15(32 \%)$ cases, where in all cases the junior assistant's name had been omitted by the surgeon writing the operation note.

Good compliance was found for documentation of procedure (100\%), incision (95\%), diagnosis in trauma (78\%), operative findings and complications in trauma (92\%), closure $(100 \%)$, and postoperative instructions (100\%). However poor documentation was found for diagnosis in elective cases (13\%), elective operative findings (70\%), and identification of prosthesis used (70\%). Of concern only $14 \%$ of notes were typed and of the handwritten notes $20 \%$ ( 8 cases) had areas that were not legible. These results are summarized in Figures 2 and 3.

\section{Discussion}

The operation notes reviewed provided a good spectrum as the types of operation and the experience of the surgeon writing the operation notes was very varied. Although generally of good standard there is room for improvement in operation notes writing as in some cases important information is being missed. Also of concern it is evident that a number of handwritten

- Details of tissue removed, added or altered

- Identification of prosthesis used, including serial numbers of prostheses and other implanted materials

- Details of closure technique

- Postoperative care instructions

- Signature

- Legible operative notes (typed if possible)

Figure I Recommendations from Good Surgical Practice ${ }^{8}$ regarding information to be included in operative notes. 


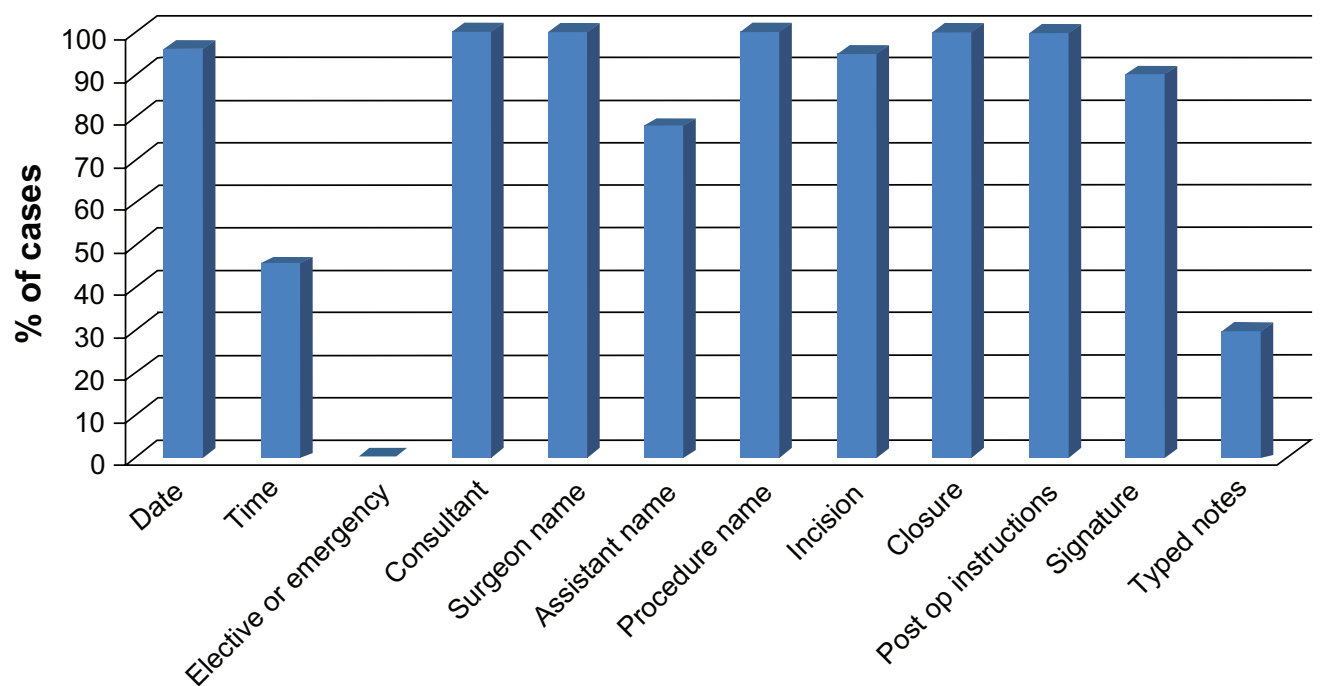

Information documented

Figure 2 Percentage of cases in which the specified information had been recorded in the operation notes.

notes had passages that were deemed illegible. Areas in which standards could be improved include meticulous scripting of all surgeons' names, operative diagnosis, findings, and mentioning of complications/problems (if relevant).

Although there is no perfect model for producing faultless operation notes, strategies to improve operation note writing in the literature can be divided into two broad categories: providing a proforma or providing an aide-memoire. Proformas have been shown to be of benefit in a number of specialities $^{1,5,9}$ as have aide-memoires. ${ }^{7}$ The literature also provides evidence of the superiority of computerized operation notes compared to hand written notes ${ }^{10}$ although these studies note the investment required both in monetary terms and in staff training.

Even so it is noted that a computer generated template detailing information to be recorded, combined with the facility for typed operation notes would improve the system by targeting the two main faults detected in this study, namely the omitting of information and the illegibility of hand written notes.

\section{Conclusion}

Although generally of good standard a proforma/template and computerized operation notes would improve the quality of operation notes in the department.

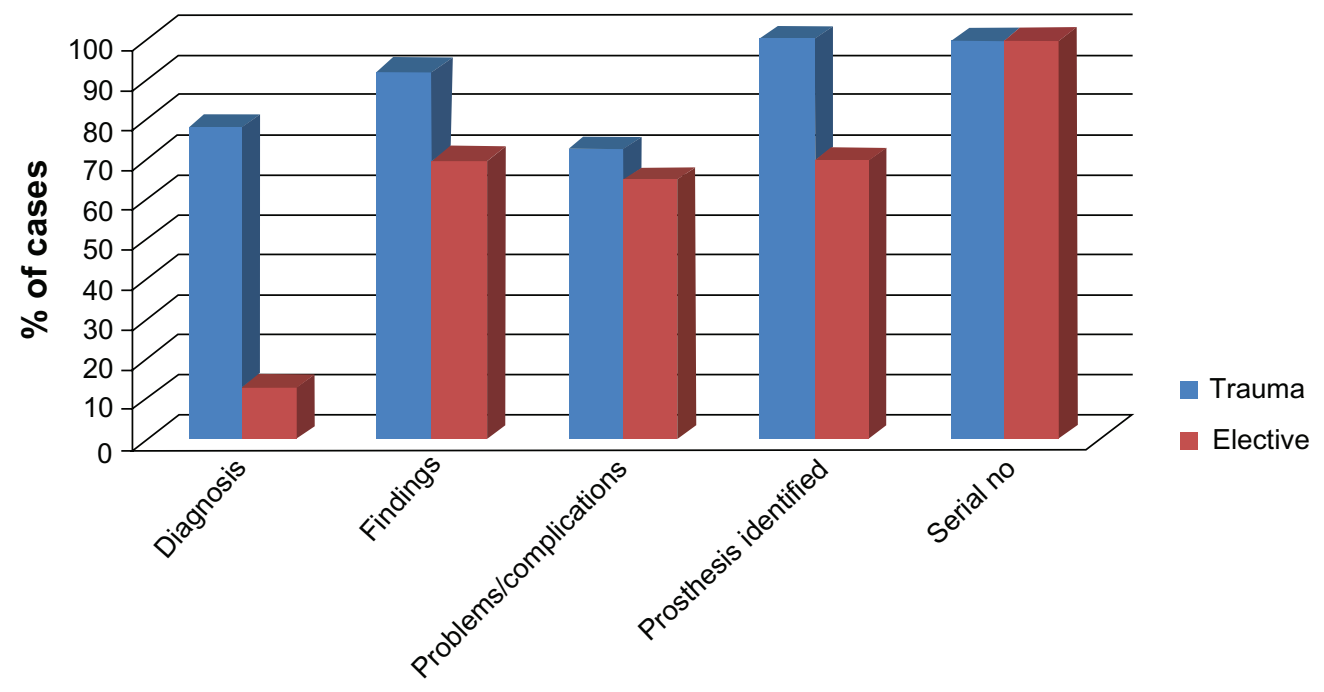

Information documented

Figure 3 Breakdown of information documented according to type of case (trauma or elective). 


\section{Disclosure}

The author reports no conflicts of interest in this work.

\section{References}

1. Al Hussainy H, Ali F, Jones S, McGregor-Riley J, Sukumar S. Improving the standard of operation notes in orthopedic and trauma surgery: the value of a proforma. Injury. 2004;35:1102-1106.

2. General Medical Council. Good Medical Practice. 3rd ed. London, UK. GMC; 2001.

3. Basad E. Importance of computer-based procedures. Planning and documentation in orthopedic surgery. Orthopade. 1999;28(3):227-284.

4. Campling E, Devlin H, Hoile R, Lunn J. The Report of the National Confidential Enquiry into Perioperative Deaths 1990. London, UK. HMSO; 1992.

5. Bateman ND, Carney AS, Gibbin KP. An audit of the quality of notes in an otolaryngology unit. J Roy Coll Surg Edin. 1999;44:94-95.
6. Morgan D, Fisher N, Ahmad A, Alam F. Improving operation notes to meet British Orthopedic Association guidelines. Ann R Coll Surg Engl. 2009;91:217-219.

7. Din R, Jenna D, Muddu BN. The use of an aide-memoire to improve the quality of operation notes in an orthopedic unit. Ann R Coll Surg Eng. 2001;83:319-320.

8. The Royal College of Surgeons of England. Good Surgical Practice. London, UK: RCSENG - Professional Standards and Regulation; 2008.

9. Rigby K, Brown SR, Lakin G, Balsitis M, Hosie KB. Use of a proforma improves colorectal cancer pathology reporting. Ann R Coll Surg Engl. 1999;81(6):401-403.

10. O'Bichere A, Sellu D. The quality of operation notes: can simple word processors help. Ann R Coll Surg Engl. 1997;79(5 Suppl): S204-S209.
Clinical Audit

\section{Publish your work in this journal}

Clinical Audit is an international, peer-reviewed, open access journal focusing on the processes and outcomes of clinical audit in any area of healthcare. All aspects of patient care are addressed within the journal and practitioners from all disciplines are invited to submit their work. Areas covered include: Publication of audits; How an audit has changed practice;

\section{Dovepress}

Practical tips on how to do audits and to avoid pitfalls; How audits have changed patient care; Calls and justifications for new audits. The manuscript management system is completely online and includes a very quick and fair peer-review system, which is all easy to use. Visit http://www.dovepress. com/testimonials.php to read real quotes from published authors. 